\title{
2008 Pisacano Scholars
}

The Pisacano Leadership Foundation, the philanthropic arm of the American Board of Family Medicine, recently selected its 2008 Pisacano Scholars. These 5 medical students follow in the footsteps of 66 scholar alumni who are practicing physicians and 15 current scholars who are enrolled in family medicine residency programs across the country. The Pisacano Leadership Foundation was created in 1990 by the American Board of Family Medicine in tribute to its founder and first executive director, Nicholas J. Pisacano, MD (1924-1990). Each Pisacano Scholar has demonstrated the highest level of leadership, academic achievement, communication skills, community service, and character and integrity.

Parker Duncan, a 2008 Pisacano Scholar, is a fourth-year medical student at the University of

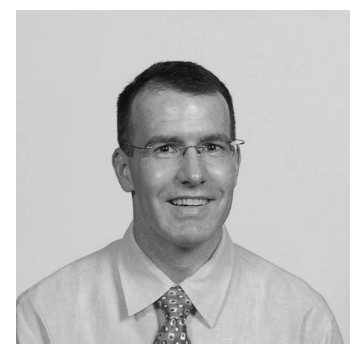

Parker Duncan California-Irvine School of Medicine. Parker graduated from Duke University with a Bachelor of Arts in Political Science on a Naval Reserve Officers' Training Corps scholarship. He subsequently served 4 years as a junior officer on the USS Nimitz (CVN-68). He was awarded the "Top Snipe" award from the Naval Engineers' School, United States Army. This award is given to the valedictorian of the class based on a combination of academic and leadership qualities. Parker just recently completed his Master of Public Health degree at California State University.

Before medical school, Parker worked for 6 years as a counselor and a manager/director in community mental health in San Francisco. He then spent a month in Quito, Ecuador, with the Child Family Health International program to gain clinical experience. He returned to Quito the next summer and worked with the incountry program directors and as coordinator and cultural translator for the student participants.

As a medical student, Parker has received a number of awards, including the Service Award from the
Associated Medical Students Government. He was also inducted into the Gold Humanism Honor Society. While attending his first American Medical Student Association Conference, Parker learned of SB 840, or the California Health Insurance Reliability Act. Soon after Parker became copresident of the AMSA Chapter at the University of California-Irvine, organizing the school's first meeting and election of officers. Parker cocreated and organized Lobby Day with a University of California-San Francisco medical student, which included a rally and legislative visits in support of SB 840 .

Parker is a member of the Board of Directors for the California Physicians Alliance; he and his cocreator for Lobby Day are the first ever student board members. He and his University of California-San Francisco counterpart served as cocoordinators for Lobby Day 2008, which had almost 3 times the number of attendees as the year before. Parker has also been a member of the Latino Medical Student Association for the last 3 years.

Parker's vision of his future career in family medicine involves a comprehensive, integrative health outpatient clinic: a full-service, outpatient center that supports proactive health. He also envisions partner clinics in Mexico or other Latin American countries. Finally, Parker's vision includes a commitment of involvement in improving his local community.

Lara Jirmanus, a 2008 Pisacano Scholar, is a fourth-year medical stu-

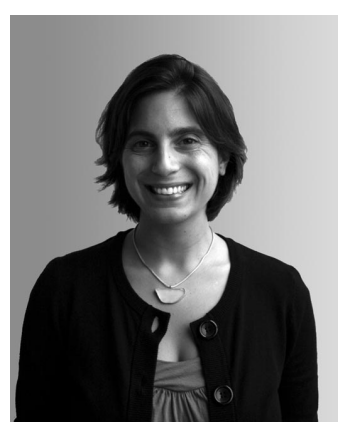

Lara Jirmanus dent at the University of Massachusetts Medical School (UMass). Lara graduated cum laude from Harvard University with a Bachelor of Arts in Biophysics. She was awarded the Harvard College Scholarship for Academic Achievement each of her 4 years there.

After college, Lara worked as a community organizer, building community coalitions in sup- 
port of local labor campaigns, immigrant rights, and universal health care. She also interned with the HIV/AIDS Department of the World Health Organization and with the Women's Humanitarian Organization in Beirut, Lebanon, in a refugee camp.

At UMass, Lara helped organize relief efforts for Hurricane Katrina, planning a talent show and art auctions to raise money for hurricane victims. Lara recently served on the national coordinating committee of the UMass Chapter of Universities Allied for Essential Medicines, helping to plan the national conference in Cambridge, Massachusetts. In recognition, Lara's classmates awarded her with the Student Body Committee Leadership Award. She also volunteers with Physicians for Human Rights and is a founding member of the Central Massachusetts Coalition for Middle East Peace.

Lara has also worked with several community organizations, including the Worcester Immigrant Rights Coalition, Women Together, and the African Health Committee. As an Albert Schweitzer Fellow in 2006/2007, Lara collaborated with a community health center in Worcester, Massachusetts, to organize focus groups to assess obstacles to health care and to ensure solutions based on the findings that would guide future health policy. Lara's experience working with the community health center inspired her, along with 3 fellow classmates, to develop and coordinate an optional elective course for medical students called "The Bigger Picture: Health Issues Affecting the Community of Worcester."

In her future career as a family physician, Lara looks forward to caring for diverse individuals and their families in underserved communities and continuing her work in community health centers, building relationships with local organizations and working together to develop health interventions.

Anne Kolan a 2008 Pisacano Scholar, is a fourth-year medical stu-

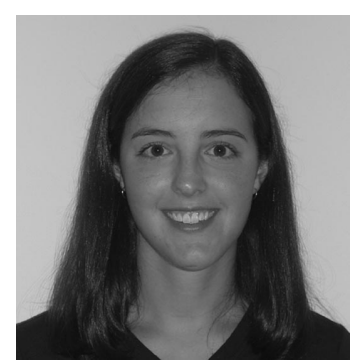

Anne Kolan dent at the University of Wisconsin School of Medicine and Public Health. She graduated with distinction from the University of WisconsinMadison with a Bachelor of Science in Biology with a focus in Environmental Studies. As an un- dergraduate, Anne was the recipient of the F. Chandler Young Travel Award to pursue her study of the Spanish language in Valparaiso, Chile. While abroad, she volunteered with the organization Dame la Mano, tutoring in the local elementary schools and providing support at an adolescent girls' home. Anne was inducted into the Phi Beta Kappa National Honor Society for her academic achievements.

After graduation, Anne was selected to participate in the Americorps National Civilian Community Corps based in Charleston, South Carolina. She spent the year traveling with a team throughout the southeast region, completing community service projects including disaster relief, trail building and maintenance, tutoring and mentoring, and house building with Habitat for Humanity.

Anne has continued her academic excellence and dedication to community service throughout medical school. She has received numerous scholarships for academic achievement. As the recipient of a clinical research apprenticeship, Anne worked closely with a family physician to explore the unique benefits and challenges for female family physicians in dual-physician relationships. While serving as copresident of the Integrative Medicine Interest Group, she helped organize the first Integrative Wellness Fair. She has been a leader in the Healer's Art elective and volunteers at the MEDIC clinics, providing free primary health care services to underserved community members. For her demonstrated kindness and professionalism, Anne was selected by her classmates to join the Gold Humanism Honor Society.

Secondary to her own pursuit of balance and wellness, Anne serves as a member of Advocacy and Intervention for Medical Students, an organization that promotes self-care while providing education, support, and advocacy for medical students. She leads by example as a dedicated distance runner, completing both the Chicago and Boston Marathons during her second year of medical school.

At the completion of her residency, Anne plans to pursue further training in the field of integrative medicine. She is excited to begin developing her own patient-doctor relationships while promoting health and wellness through a sustainable and interdisciplinary health care approach.

Lars Peterson, PhD, a 2008 Pisacano Scholar, is a fourth-year medical student at Case Western Reserve University and a native of Richfield, Utah. 


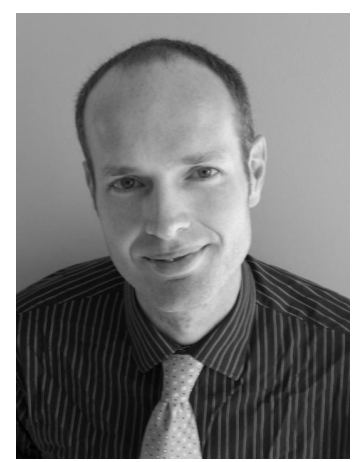

Lars Peterson, PhD
Lars earned bachelor's degrees in both biology and anthropology from the University of Utah. While enrolled at Utah, Lars was involved with the Student Health Advisory Committee and served as the associate editor for Utab's Health, a student-run journal that published data on and original research about the health of Utahns.

In 2002 Lars left Utah to enroll in a dual MD/ $\mathrm{PhD}$ program in Health Services Research at Case Western. During the first 2 years of medical school, Lars was selected to join the Primary Care Track, a program to foster leadership and advanced clinical skills in primary care. He also was selected to participate in a medical education curriculum development program. Lars has served in multiple leadership roles in family medicine at the local, state, and national levels. He was a coleader of his Family Medicine Interest Group for 3 years, and his work on implementing a journal club and a program for third- and fourth-year students helped his Family Medicine Interest Group earn its first ever Program of Excellence award from the American Academy of Family Physicians. At the state level Lars served for 2 years as the chair of the Student Affairs Committee and also as the student representative on the Board of Directors of the Ohio Academy of Family Physicians. He also served on the American Academy of Family Physicians commissions on science and practice enhancement.

Lars' research has focused on how community-level characteristics affect both health status and access to health care and whether this relationship varies by rural or urban status. He has 3 first-author, peer-reviewed manuscripts and has made numerous oral and poster presentations. His commitment to rural health, rural health research, and involvement with the Ohio Rural Health Scholars program earned him the Student Leadership Award from the National Rural Health Association.

Lars envisions a career of patient care and research that seeks to validate the value of family medicine to both the health of individuals and the health care system and to understand community- level effects on access to health care and health status.

Olga Valdman, a 2008 Pisacano Scholar, is a fourth-year medical stu-

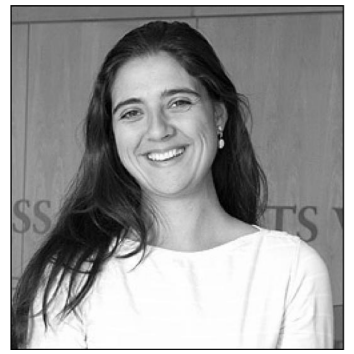

Olga Valdman dent at the University of Massachusetts Medical School (UMass). Olga graduated cum laude from Barnard College at Columbia University with a Bachelor of Arts in Psychology. Olga participated in a number of research projects as an undergraduate, including research for her senior thesis, an experiment that she designed and implemented. Olga received a Travel Award from the International Society of Developmental Psychobiology to its annual conference, where she presented a poster on her research.

At UMass, Olga has continued her academic success and community service. As copresident of the Student National Medical Association, she received the Unipartnership Award for a tutoring program for African children that she led establishment of at UMass. This program partners with a community organization to provide tutoring for children who are recent refugees from various African countries. Olga later cofounded a nonprofit organization called African Community Education program. This program's mission is to bring the community together and start a Saturday school for the children, where African adults serve as teachers, tutors, and volunteers working alongside non-African teachers and tutors in Worcester. Olga continues to colead the program, which now serves 60 children from a number of African countries and recently received funding from the Massachusetts Department of Education.

As president of the International Health Interest Group during her second year of medical school, Olga developed and organized an international service project in La Romana, Dominican Republic. This service project is now an annual spring break trip for dozens of medical students, nursing students, and faculty. They offer care to the most medically underserved populations working under the supervision of Dominican and American physicians of many medical specialties. Olga took an extra year of medical school to develop a portable 
paper medical record-keeping system for each patient of the bateyes (villages on sugarcane plantations). She is working closely with all hospitals in La Romana as well as the regional office of the Ministry of Health while conducting a 1-year pilot study about the sustainability and utility of this system. Olga has received a scholarship and multiple grants and travel awards to help fund her ongoing work in La Romana.
Olga's experiences with so many diverse people and cultures have humbled her and taught her to see each person first and foremost as an individual. As a family physician, Olga hopes to be able to provide the best quality care to patients from all over the world.

Jane Ireland American Board of Family Medicine Communications 